\title{
GEO-SOCIAL TAGGING AS A CREATIVE WAY TO COMMUNICATE STORIES ON GEOGRAPHIES
}

\author{
Elisa Bonacini ${ }^{1}$ \\ e-mail: e_bonacini@hotmail.com
}

Diterima : 21 April 2012 / Disetujui : 19 April 2013

\begin{abstract}
The aim of this paper is to show how the evolution of ICTs in the field of digital cultural participation has helped turn geo-social tagging into a new form of creation of cultural value through user-generated contents (UGC). In order to demonstrate the potential of these digital tools, we will base our study on some examples of geotagging and geo-social blogs, in Italy and abroad. Tagging a place is giving that place a story: this means being able to write digital stories on geographies. Tagging a place enables us to rediscover our territory in a new and shared way, creating forms of real social tagging and urban digital storytelling.
\end{abstract}

Keywords: geo-social tagging, geoblogs, real social tagging, urban digital storytelling, stories on geographies, geo-wiki, user generated content, digital culture, digital culture participation, digital collective memory, cultural value.

\section{INTRODUCTION}

The exponential evolution of digital content creation has led to a real cultural revolution, where ICTs have become increasingly dominant. So much so that L. Manovich (Manovich 2008, Manovich 2011) defines contemporary society as a software society, whose cultural output is what he calls a software culture. In this software culture there are specific cultural processes (creating, distributing, receiving and sharing both information and knowledge), which are mediated by dedicated digital tools, software or applications. These processes are briefly described below based on the contribution of the author:

- software programs that allow users to create, share and make accessible cultural contents that contain digital representations, ideas and aesthetic values (e.g., programs

1. Menempuh pendidikan di University of Catania Piazza Università 16, 95124 Catania (ITALY) 
that allow users to publish documents and, as such, must be defined as media softwares, like Microsoft Word, Powerpoint, Photoshop, Illustrator, Firefox, Internet Explorer, Blogger, etc..);

- software programs that provide interactive cultural experiences (from PC games to platforms like Second Life, all of which offer three-dimensional reconstructions that you can "experience" in virtual life);

- software programs that allow users to create and share information and knowledge online, for example, programs that facilitate open access participation to Wikipedia or geotagging social platforms (adding places on Google Earth with Google My Maps, on geo-social networks such as InstaMapper, Foursquare, Google places, Facebook places or Gowalla, all of which provide new ways of reading and understanding of places, but also on georeferenced blogs, i.e. geoblogs);

- software featuring communication tools such as text, voice and/or video (e.g., e-mail, instant messaging, posts or pokes on other users' "walls" or profiles, chat, voice/ video chat...);

- software programs that allow users to be part of a kind of on-line "information ecology", forms of social bookmarking through which digital contents can rank higher in web searches based on how many people are sharing and liking it (for example, when users click the +1 on Google + or Like on Facebook). According to Manovich: <The exponential explosion of the number of people who are creating and sharing media content, the mind-boggling numbers of photos and videos they upload, the ease with which these photos and videos move between people, devices, web sites, and blogs, the wider availability of faster networks - all these factors contribute to a whole new "media ecology"> (Manovich 2008);

- software built to help develop other programs able to support all these activities.

We can then agree with Bastos (2010) when she states that technology has created $<$ an umbrella of art forms that use emergent media, platforms and digital tools. Examples are 2D or 3D computer designs called digital imaging, digital photography, sculpture, digital installations and virtual realities, Net Art (meaning internet art, also called web-art), performance, sound art and electronic music, digital animation and video, software, databases, interactive systems, projections and game art>.

In this software culture, geo-social blogs (or geoblogs) and geo-social networks are among the latest innovations to redefine the world of digital communication and cultural activities, especially when we consider user-generated cultural content (UGC). These trends were already discussed in a previous work (Bonacini 2011), but we will describe them in further detail here.

Geoblogging could be described as a way to write stories on geographies, an interface that allows registered users to leave a comment or add an event related to a specific place (referred to as geotagging a place). These posts are displayed on a map, where they can be read by simply clicking on the location.

Geoblogging is also widely used as a tool to improve land-use planning and environmental monitoring, as well as data dissemination and sharing through GIS technology. In fact, geoblogs are often used for Development Planning, Zoning and Urban Planning (in Italy, Sardinia's Regional and Urban Planning is currently being tested).

Geo-social networks use geographical services such as geocoding and geotagging to illustrate the social dynamics of a city. They create new digital maps that are fluid and always synchronized. These real-time living maps of the city allow for a quick, almost immediate, exchange of geo-social information (Schuch Brunet \& Freire, 2010) and can be understood as $<$ a contemporary merger between a classical digital territory map and a dynamic localized 
flows representation producing a new kind of visual information where places, people, activities, and time are mixed together> (Aguiton, et at. 2009).

Although they work in different ways, both geoblogs and geo-social networks enable similar forms of geo-social tagging that help transfer the social benefits of participation, connection and interaction into the city's geography. This creates what has been defined as Geography 2.0 or Neogeography, a form of informational geography voluntarily created by users: <free, easy to use, and yet potentially very powerful in terms of its impact on geographical information sciences, social sciences, and its capacity to encourage a new partnership between professionals, lay practitioners, and the wider public > (Hudson-Smith, et al. 2009).

Another type of digital cultural activity that could be described as neogeography would be adding places to Google Earth via the Google My Maps application. In fact, according to Faber (2009) the geo-social tagging revolution can be attributed to the introduction, in early 2005, of Google My Maps, an application inside Google Maps: <the Google My Map (GMM) application allows users to add digital content (text, video, paths, shapes, photos) to a satellite-imaged map of Earth, creating a personalized and annotated mashup that can be shared online with anyone in the world>. You can choose to keep your own maps private or you can publish or export them to Google Earth.

This process could be described as crowdsourcing ${ }^{1}$ since it brings together georeferenced information and experiences from different sources by allowing <multiple users from across geographical regions to collaborate on a single map, effectively allowing you to harness collective intelligence through crowd-sourcing - many voices contributing to one dataset based on their own localized knowledge and experiences> (Faber 2009).

There are many programs designed to create custom maps based both on Google Maps and geographical crowdsourcing: for example, GMap Creator and MapTube, both created by the Centre for Advanced Spatial Analysis (CASA) at the University College London (Hudson-Smith, et al . 2009). There are also open source geographical projects, that are free and collaborative: for example, OpenStreetMap (www.openstreetmap.org: fig. 1) and Wikimapia (http://wikimapia.org: fig. 2), a kind of geographical wiki based on Google Maps and linked to Wikipedia pages.

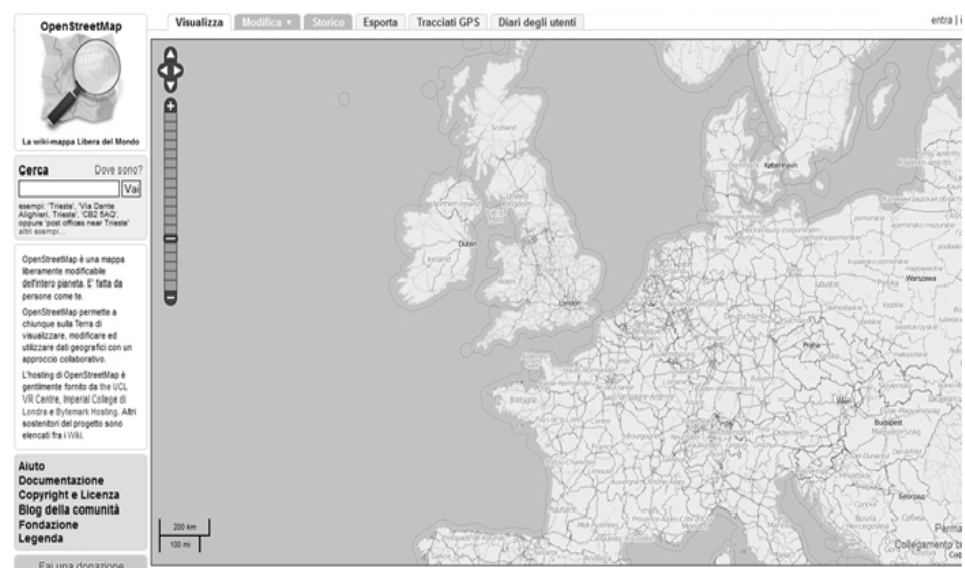

Fig. 1. OpenStreetMap.

Vol.6 No.3 - Mei 2013 


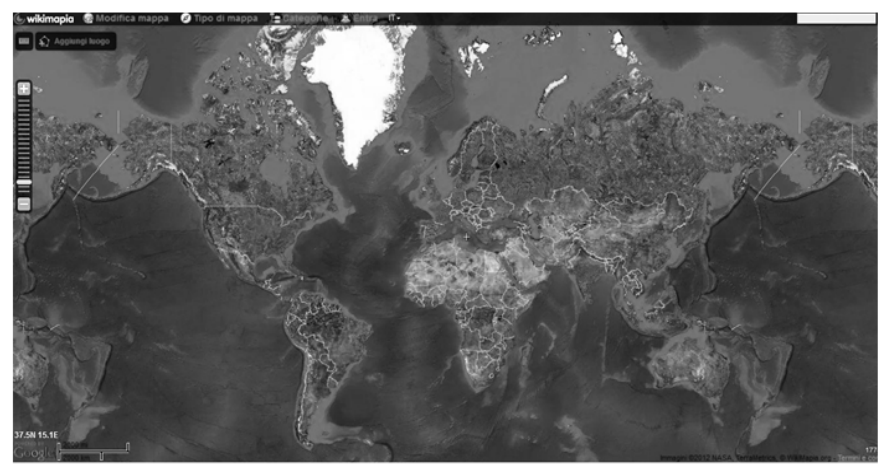

Fig. 2. Wikimapia.

\section{Stories on geographies: geotagging social, social tagging and urban real digital story telling}

The geo-social blogs that are presented here work in similar ways, with some slight differences. They usually feature maps from Google Maps, on which users can see the posts written and shared by other users (messages, news, commentaries, emotions, advertising information), thereby creating what has been defined as real social tagging, i.e. a network of labelled content spread all over a digital area that is actually and emotionally experienced by its citizens (hence the term "real"). This is a new form of interaction between society, geography and technology, described by some as a form of urban digital storytelling (Levialdi Ghiron, et al. 2009) that allows people to create a digital territory, where they can store digital memories: <there is no forgetting, no memory loss in "Digital Territory"> (van Kranenburg, 2008).

Along the lines of Google My Map, in November 2006 the Museum of London launched Map My London (www.mylondonmap.com: fig. 3), a geo-website where Londoners could enter their “memorable London moments onto a large interactive digital map" (this is the website's tag line).

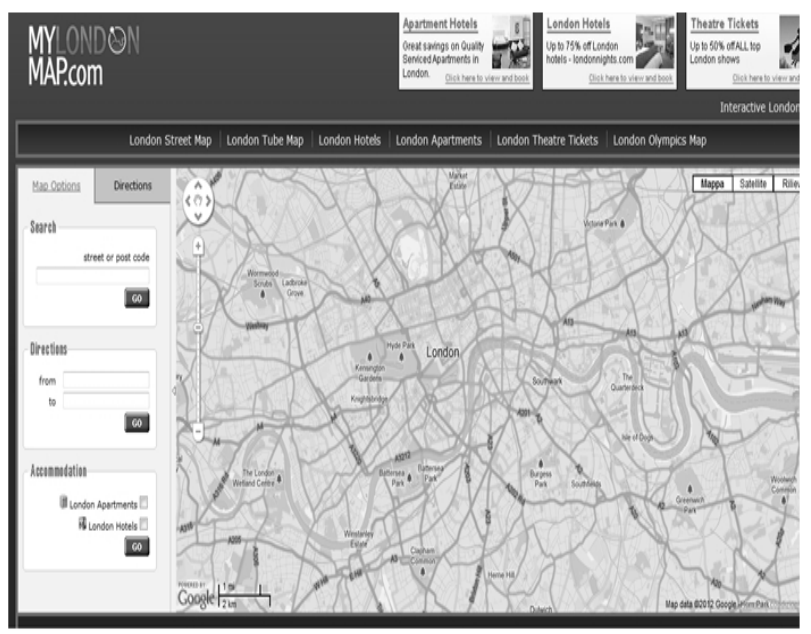

Fig. 3. MyLondonMap. 
There are a few examples of geoblogs in Italy.

Mappa Emozionale dei Luoghi della Memoria Antifascista a Torino (Emotional Map of Anti-Fascist Memory in Turin: http://acmos.net/memoria/: fig. 4) is a geoblog set up by Performing Media Lab during the "2006 Winter Universiade" at the Multi-site Museum of Resistance, Deportation, War, Human Rights and Freedom of the city of Turin. Although this project is no longer active, it was a remarkable example of the combined use of two different technologies, namely QR codes and geo-social tagging, and two different communication platforms (internet and mobile phones). The combined use of geoblogging and matrix codes made it easier to reach younger generations, who are used to these types of digital languages and technologies. In this way, the Museum was able to effectively share contents related to World War II, the Resistance movement and the Holocaust with youths who do not have a direct connection with that period of history. A number of historical landmarks around the city were accessible through the Museum's website (www.museodiffusotorino.it), which featured an interactive localization map for "places of remembrance", developed by the official City of Turin website, within an experimental urban geo-wiki called MappaTo (fig. 5). At the same time, QR codes were displayed around these landmarks in order to turn the "real" visit around the city into a digital experience of decoding interactive data (textual or audio-visual cultural contents) using a smartphone. In both cases, visitors (actual or virtual) could express their feelings or reactions by leaving messages related to the different locations or digital contents. Messages were automatically linked to the geoblog Emotional Map of Anti-Fascist Memory in Turin, where they could be shared with other users and visitors, thereby creating a form of real social tagging.

Performing Rome (www.geoblog.it/performingroma: fig. 6) and Urban Experience (www.geoblog.it: fig. 7) are two geoblogs which can be used to track events or information about Rome through user-generated posts (as well as multimedia contents) that are displayed on a Google Map. Users can post their written or audiovisual diaries and describe specific locations through their subjective stories. This interaction develops a new relationship between networks and physical locations, it creates new ways to look at the territory: from the ground, through the actions and memories of users (rather than from above, through the eye of the satellites).

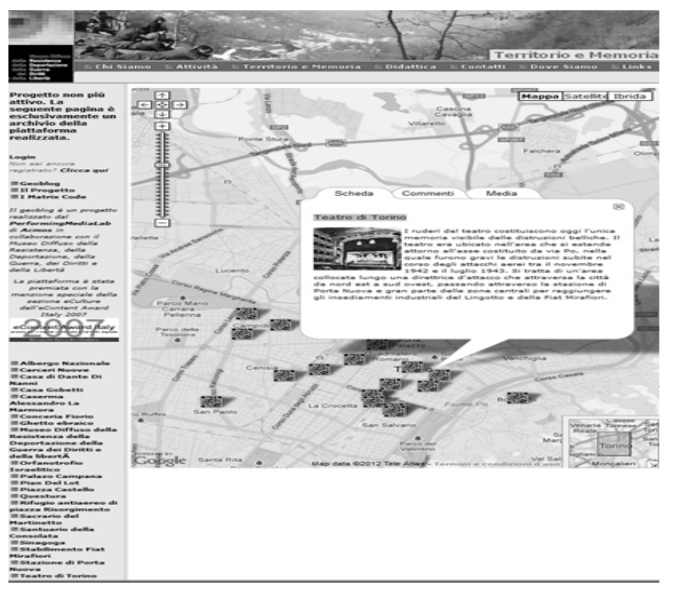

Fig. 4. Emotional Map of Anti-Fascist Memory in Turin. 


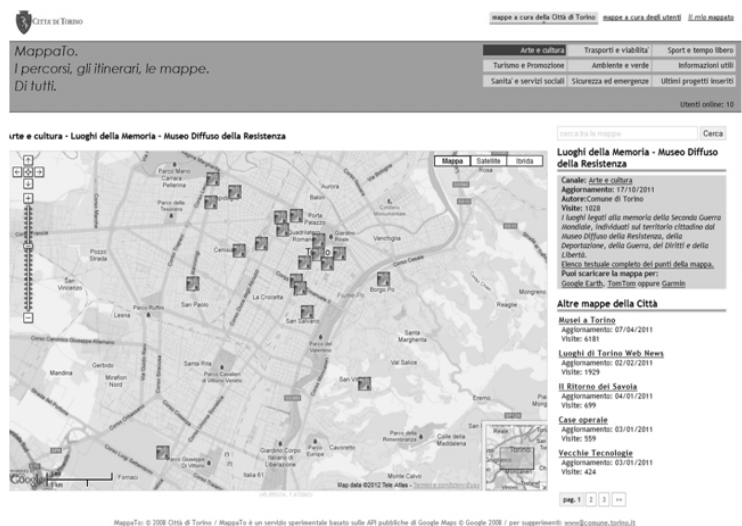

Fig. 5. Emotional Map of Anti-Fascist Memory in Turin on MappaTo.

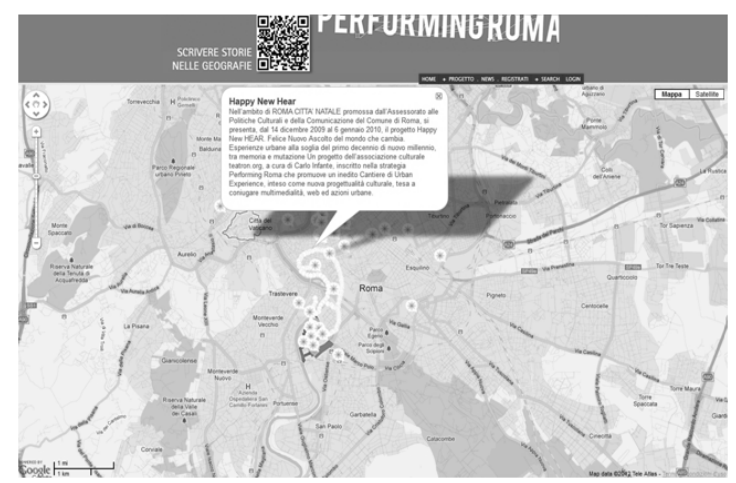

Fig. 6. Performing Roma.

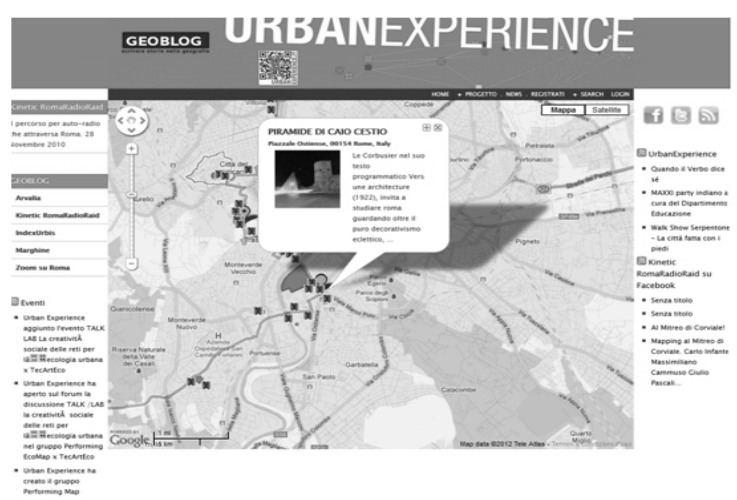

Fig. 7. Urban Experience - Roma. 
Percorsi Emotivi (Emotional Pathways: http://percorsi-emotivi.com/: Fig. 8) is a Bologna-based geoblog, created in 2008 by a research team at the Laboratory for Urban Maps at the Gramsci Institute Foundation Emilia-Romagna. Born from the desire to analyze qualitatively Bologna's inhabitants' perception of their own city, Percorsi Emotivi has become a real "call for tales", a digital container of impressions, feelings and emotions that people experience when walking the streets of Bologna. This project is a qualitative analysis and, as such, it has no real statistical value, but it is a great way to illustrate the many ways in which people experience the city. As evidenced in Fig. 8, posts submitted by users are color-coded based on their topic (What you remember, What we are, What we would like, What you discovered, What you love, What you fear, What else). The selected post in Figure 8, for example, was written by a girl who associates this place to the memory of her first kiss.

In the section I luoghi della memoria (Memory places), Percorsi Emotivi offers the geolocation of specific historical moments, while the section Guerra in città (War in the city) is dedicated to historical landmarks of the Second World War (Fig. 9). Finally, La Certosa is a section that highlights the most important moments of the history of the cemetery of Certosa (Fig. 10).

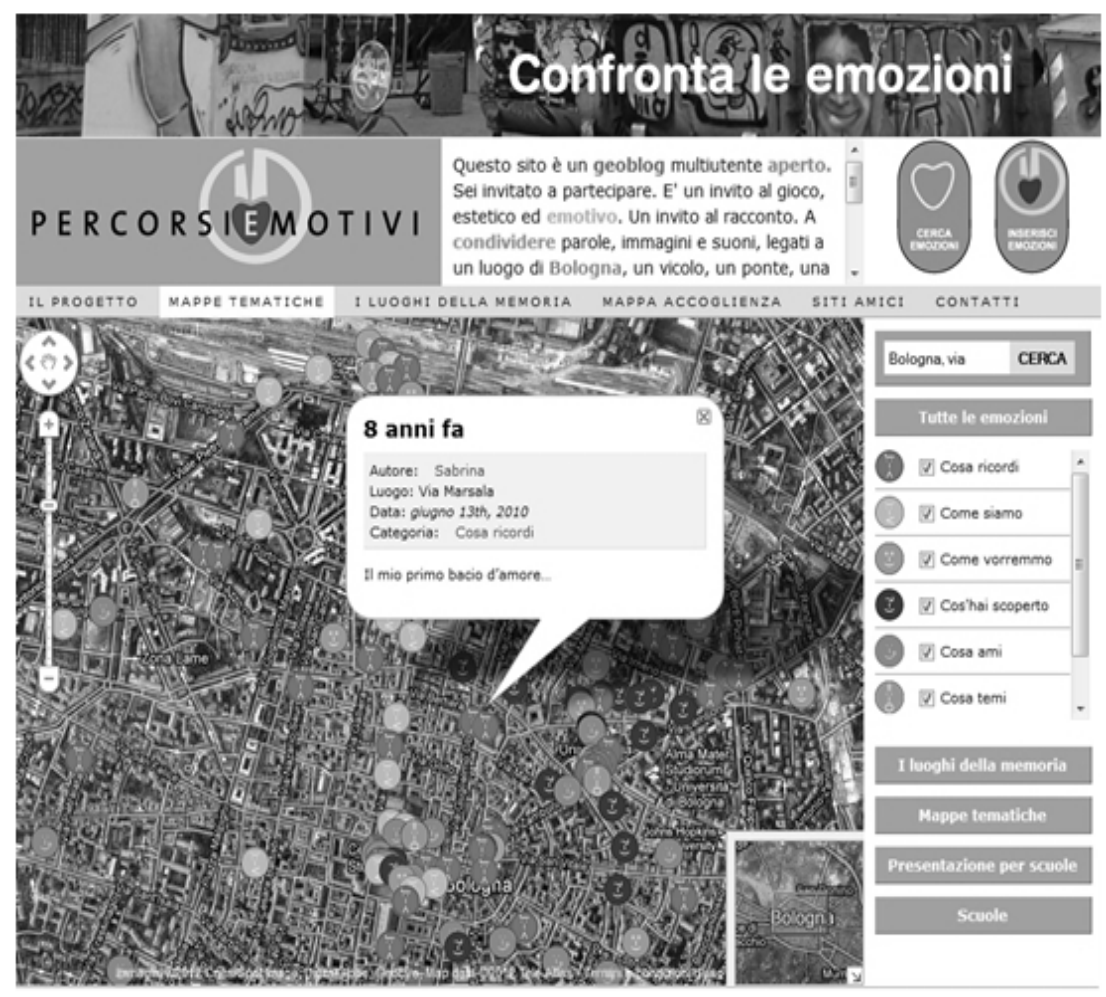

Fig. 8. Percorsi Emotivi - All the emotions - Bologna. 


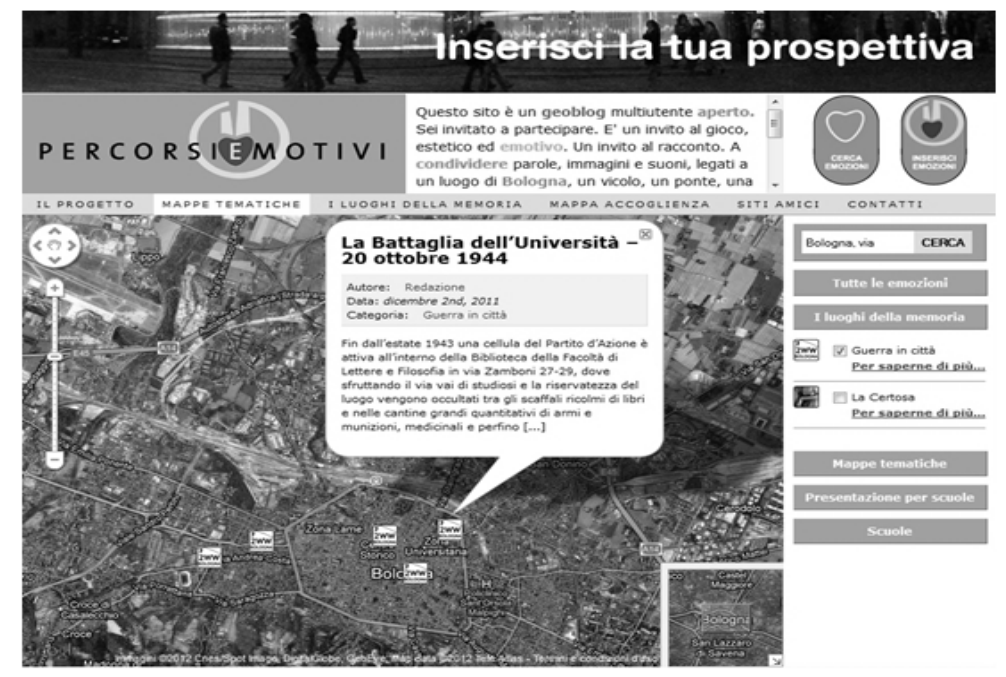

Fig. 9. Percorsi Emotivi - War in town - Bologna.

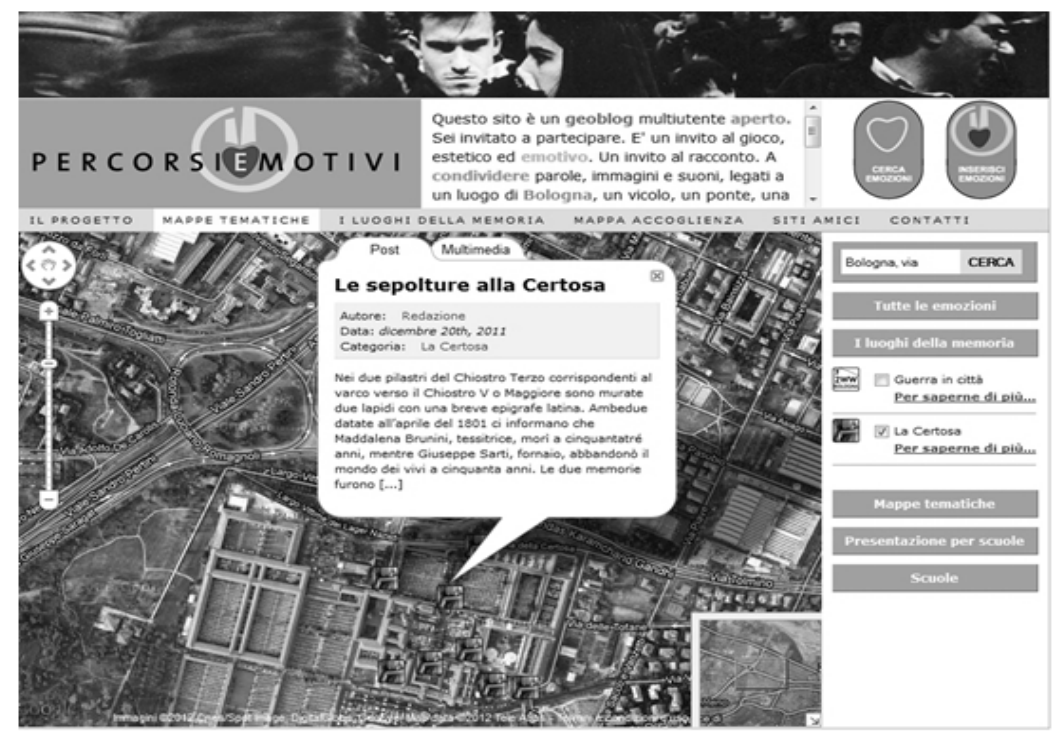

Fig. 10. Percorsi Emotivi - Certosa cemetery - Bologna.

At the bottom of the Percorsi Emotivi homepage, users can find two banners that link to Bologna's other geoblogs. The first site is Bologna ArtFirst (http://artfirst.percorsiemotivi.com/: Fig. 11), a project launched in 2010 (now in its third edition) in collaboration 
between the City of Bologna and Arte Fiera. It is an "art route" designed as one big group exhibition stretching across the whole city and its surroundings, a multimedia experience between art and history through images and installations created by artists working with the galleries present at Art Fiera. The project, titled Here and Now, showcases different locations that are part of the contemporary art circuit but also have strong historical significance.

The second example is Mamboedu.maps (http://mamboedu.maps.percorsi-emotivi.com/ : Fig. 12), a geoblog that focuses on creating emotional routes for children and teenagers. Through this project, in collaboration between the Education Department of MAMbo (Museum of Modern Art of Bologna) and the course of Communication and Art Education of Fine Arts Academy in Bologna, groups of children aged 5 to 10 mapped an entire neighborhood of Bologna during the 2010/2011 school year. The aim was for the children to get to know their own neighborhood by involving them on an emotional and aesthetic level and making them explore this well-known urban environment in search of new emotions and images. Children walked around the area, met neighbors and found out about the history of buildings, monuments and streets. This emotional contact with the environment helped them create new bonds with this urban space, filled with new memories and stories after this experience. Now this neighborhood, along with the stories and feelings reported by the children, lives through the geoblog.

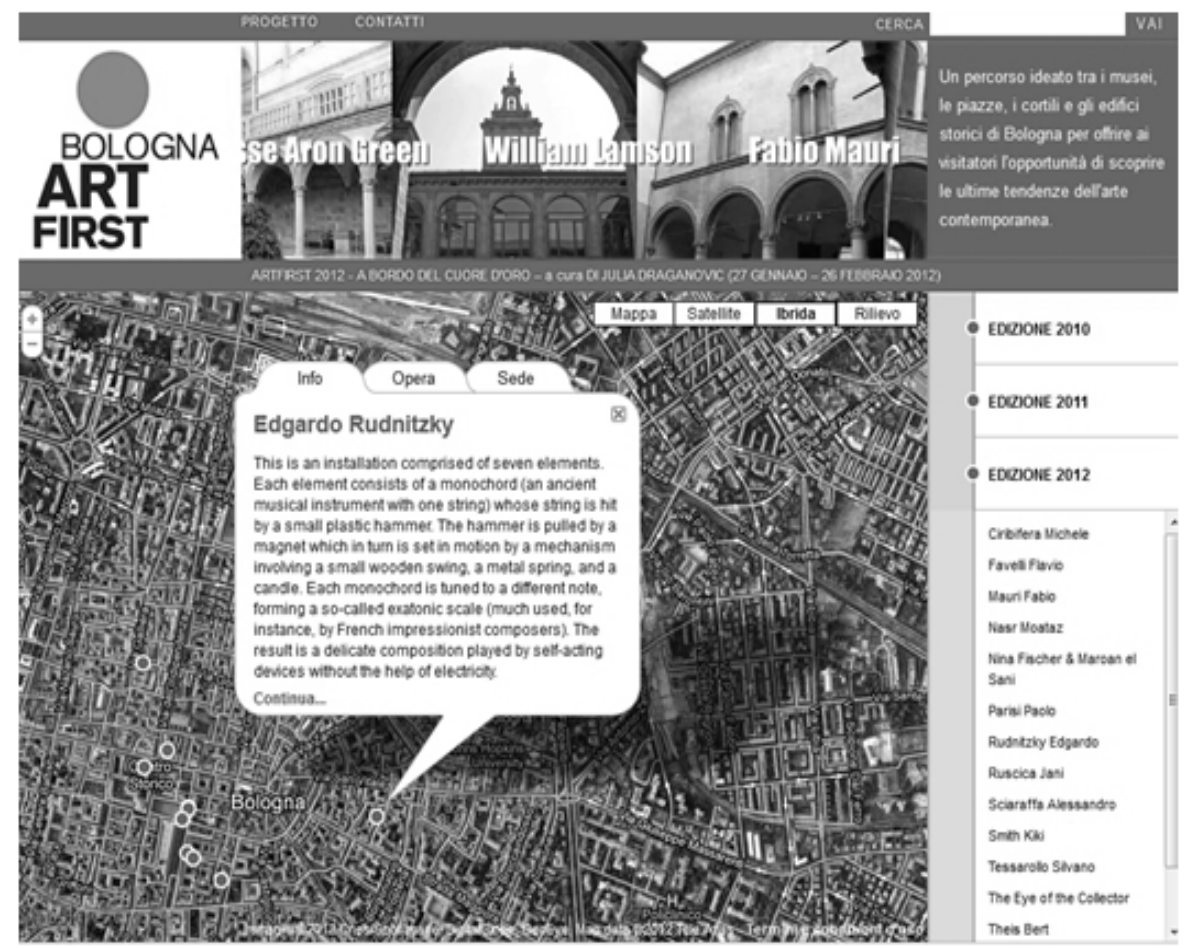

Fig. 11. ArtFirst - Percorsi Emotivi - Bologna.

Vol.6 No.3 - Mei 2013 


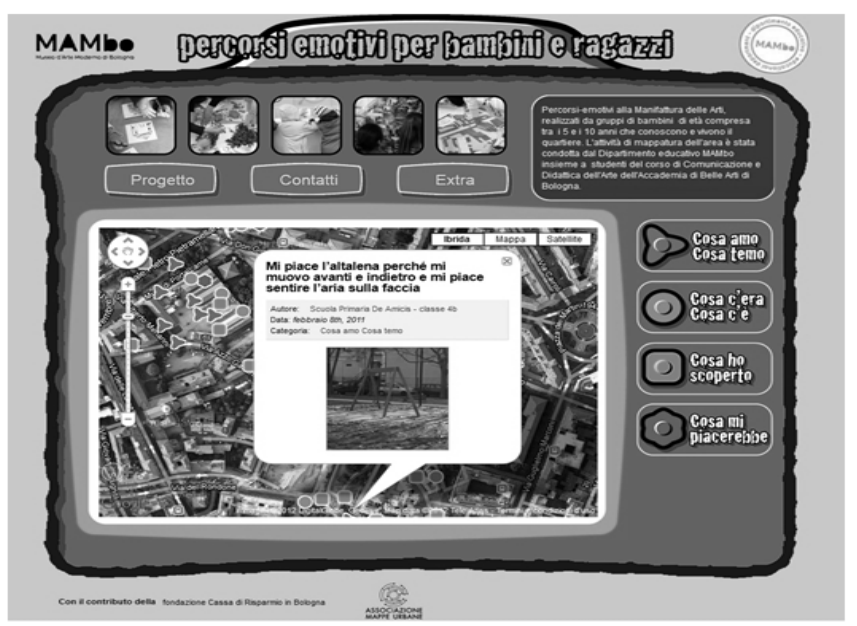

Fig. 12. MAMboedu.map - Percorsi Emotivi - Bologna.

Based on the experience of the emotional geoblog created in Turin and within an eCulture project (eContent Award Italy 2007), Performing Media Lab has created a sort of "big European multi-site museum" of Fascism and Holocaust Remembrance in Europe with a geoblog entitled StoriesOnGeographies. A European participatory geoblog of memory (http:// storiesongeographies.eu/: Fig. 13). The aim of this project is to preserve European social memory over time with the use of new technologies and it is achieved through an open access geoblog that distinguishes contents posted in three categories: Museums Entries, Associations Entries and Users Entries. Each item included on the map of Europe can be commented on by other users.

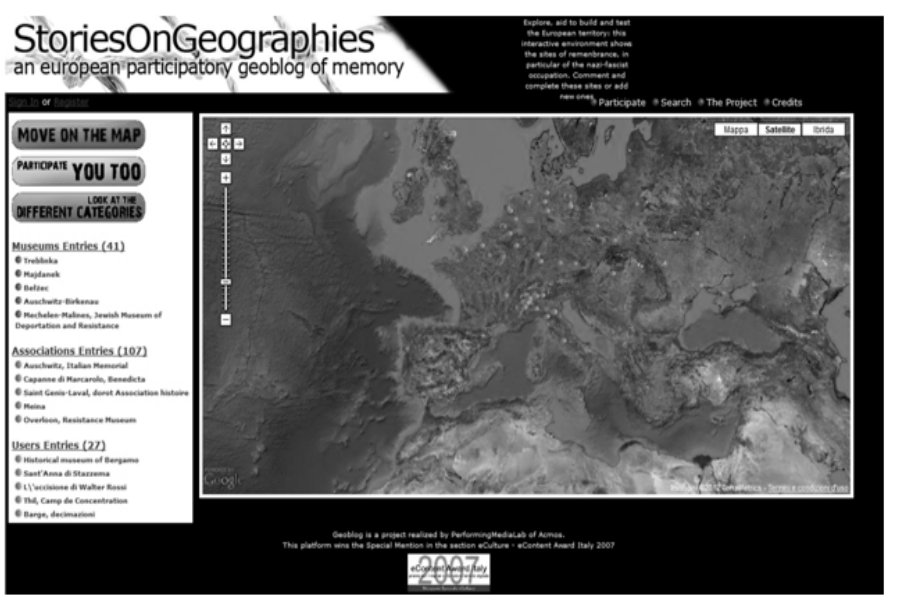

Fig. 13. StoriesOnGeographies. 
Much more complex is the project for a three-dimensional reconstruction of the historic center of L'Aquila, devastated after the April 2009 earthquake and never rebuilt. Titled Comefacciamo (How do we do this?) the project was launched by a British architect with the help of Google and the use of Google SketchUp software. ComeFacciamo is connected with the geo-website noilaquila.it (We L'Aquila: www.noilaquila.com/: Fig. 14-15), launched in June 2011 to promote the three-dimensional virtual reconstruction of the city of L'Aquila (Fig. 16) through the use of images or videos of the city, along with former residents' memories. The motto of the portal is "Sharing memory to rebuild the future". Memories, video and photos are provided and shared by users with the sole purpose of preserving, at least digitally, the memory of L'Aquila and its significant artistic and cultural heritage through a kind of urban digital storytelling. This idea is a pilot project that Google intends to make available to all communities affected by natural disasters in the world (Japan, for example, is already among the first countries to have implemented it).

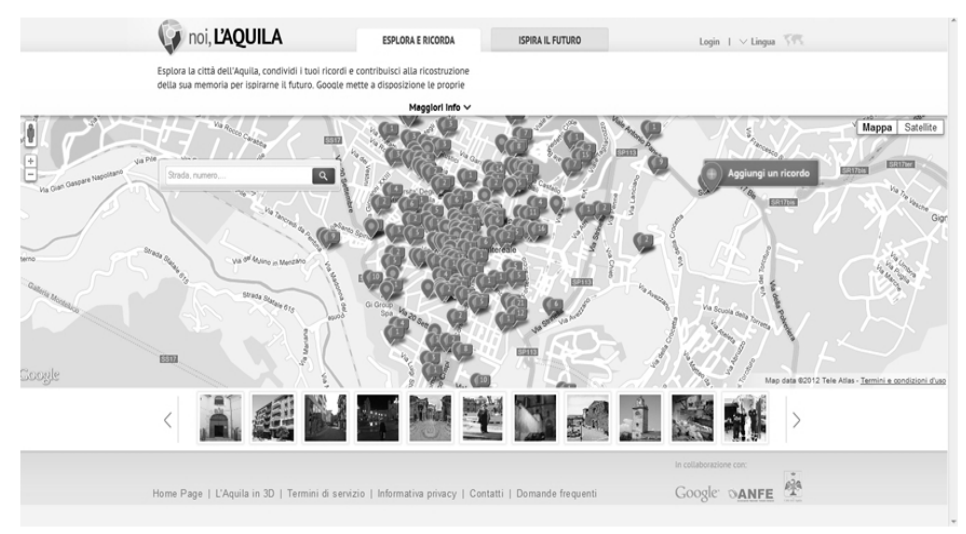

Fig. 14. Noilaquila - UGC on the map of L'Aquila.

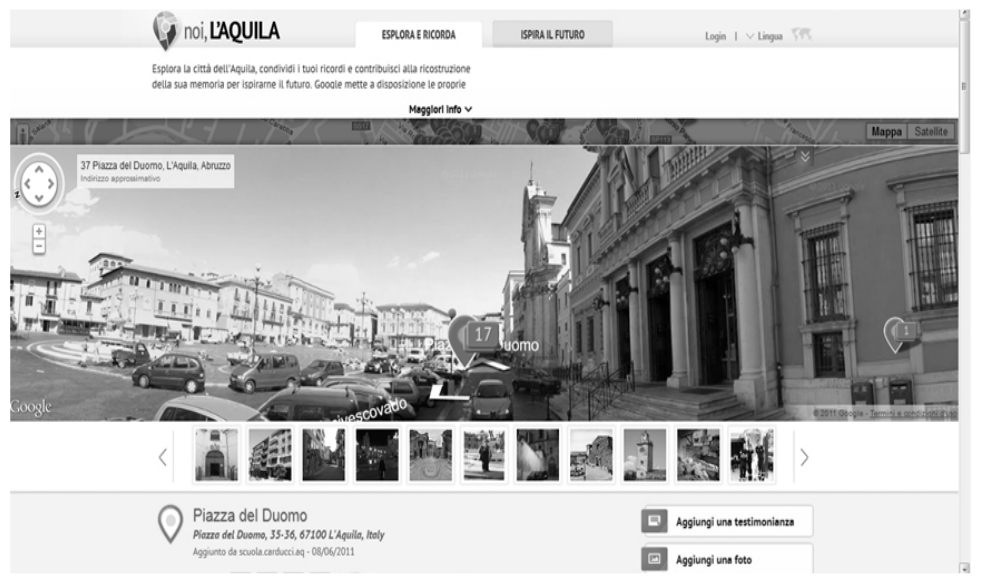

Fig. 15. Noilaquila - Duomo’s post seen on Google Street View. 


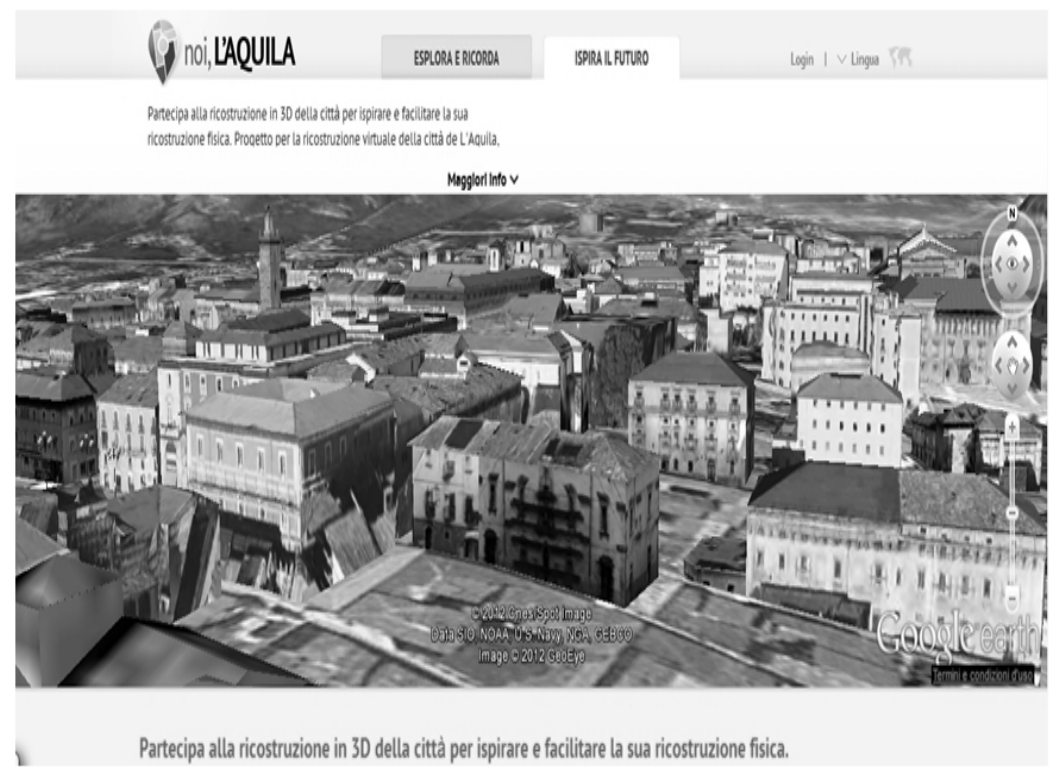

Fig. 16. Noilaquila - L’Aquila: three-dimensional reconstruction.

[[[Murmur]]] (http://murmur.info/) is another example of urban digital storytelling in which stories and memories are linked to places through digital technology. This is a Canadian project that originated in Toronto in 2003 (Fig. 17) with the collaboration of the CFC Media Lab and adopted in the following years by other cities in Canada, Ireland, Scotland, Australia, United States and Brazil. To quote Mercer (2011), [[[Murmur]]] is actually <a "location-based mobile phone documentary project" which places various marked "murmur listening spots" around a city where people can call a number and get the history, texture and experiences of the place where they are standing from the people who have lived or worked or played there. This is history and narrative "from the ground up" and not the official history of the place. It is based on and narrated by people often overlooked in the official histories. With a 3G phone or a laptop you can also listen to the stories remotely by going to the web site and clicking on the red dots on the city maps. This is turning spaces into places: giving them stories and narratives that you are probably unaware of and through the "threadlike, wiry, stringy and capillary" networks of both the city and mobile telephony, invest that place with a culture of its own>. [[[Murmur]]] is further described on the website: <It's history from the ground up, told by the voices that are often overlooked when the stories of cities are old. We know about the skyscrapers, sports stadiums and landmarks, but [murmur] looks for the intimate, neighbourhood-level voices that tell the day-to-day stories that make up a city. The smallest, greyest or most nondescript building can be transformed by the stories that live in it. Once heard, these stories can change the way people think about that place and the city at large. [...] By engaging with [murmur], people develop a new intimacy with places, and "history" acquires a multitude of new voices. The physical experience of hearing a story in its actual setting - of hearing the walls talk - brings uncommon knowledge to common space, and brings people closer to the real histories that make up their world $>$. 


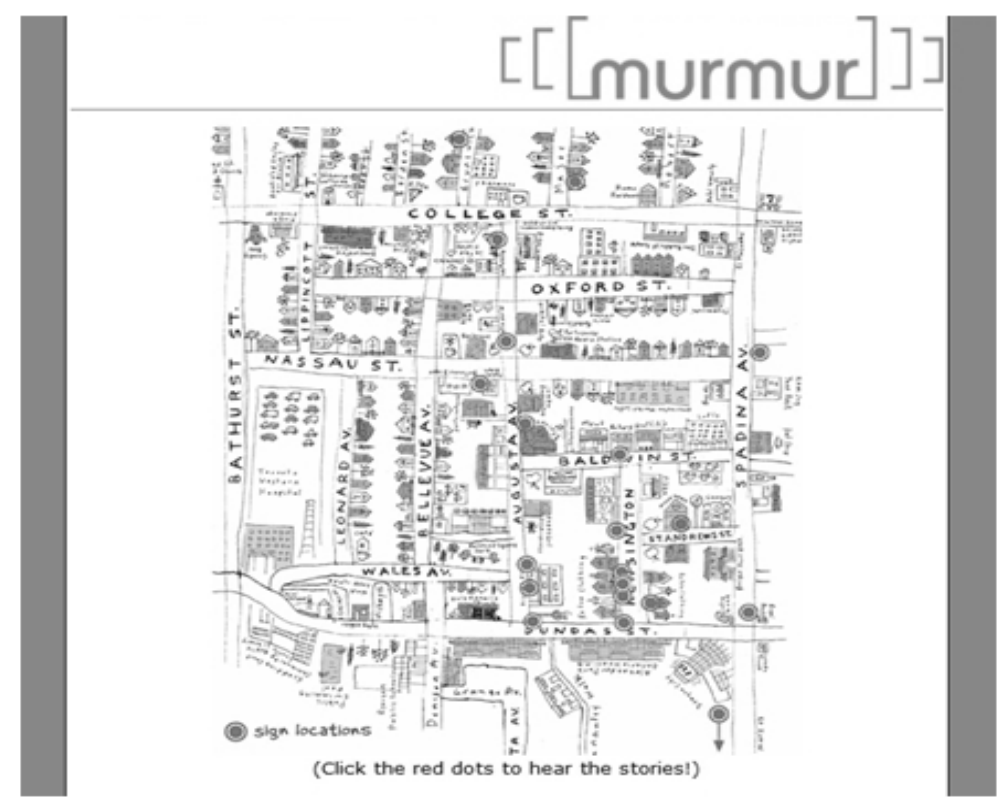

Fig. 17. [[[Murmur]]] - Kensigton Market in Toronto.

\section{Conclusions}

Geo-social tagging is certainly one of the most important digital tools for web evolution from 2.0 to 3.0 and, together with all other digital platforms, it is instrumental in increasing the weight of user-generated digital cultural information. The accumulation of new cultural contents, filled with symbols, meanings, experiences and knowledge, undeniably increases the semantic value of the information that is being collected and, consequently, its own economic value (Valentino 2008).

The evolution of ICTs gives new weight to what M. Castells (1991) described two decades ago: <local societies [...] must preserve their identities, and build upon their historical roots, regardless of their economic and functional dependence on the space of flows. The symbolic marking of places, the preservation of symbols of recognition, the expression of collective memory in actual practices of communication, are fundamental means by which places may continue to exist as such>.

\section{Bibliography}

1. Aguiton, C., Cardon D., Smoreda, Z. (2009). Living Maps. New data, new uses, new problems. Lecture for the conference First International Forum on the Application and Management of Personal Electronic Information October 12-13, 2009 MIT, Cambridge, 2009. Accessed on March 20, 2011 from: http://senseable.mit.edu/engagingdata/papers/ ED_SI_Living_Maps.pdf. 
2. Bastos, A. (2010). Discovering digital cultural capital in London's events of art and technology: reviewing the last decade, in Seal, A., Bowen, J., Ng, K. (Eds), EVA London 2010: Electronic visualisation \& the arts. Proocedings of a conference held in London, 68 July, London. London: BCS, 1-7.

3. Bonacini, E. (2011). Nuove tecnologie per la fruizione e la valorizzazione del patrimonio culturale. Roma: Aracne Editrice.

4. Castells, M. (1991). The Informational City, Economic Restructuring and Urban Development. First paperback edition. Oxford: Basil Blackwell.

5. Faber, M. (2009). Google Maps: A Tool for the Youth Media Field. Youth Media Reporter, 12 June 2009. Accessed on February 18, 2010 from: http://www.youthmediareporter.org/ 2009/06/google_maps_a_tool_for_the_you.html.

6. Hudson-Smith, A., Batty, M., Crooks, A., Milton, R. (2009). Mapping for the Masses. Accessing Web 2.0 Through Crowdsourcing. Social Science Computer Review, 4, 524538.

7. Levialdi Ghiron, S., Medaglia, C. M, Perrone, A. (2009). “Art-sonomy”: Social Bookmarking of Real Artworks via Mobile Applications with Visual Tags Source. Proceedings of the 5th International Conference on Universal Access in Human-Computer Interaction. Part III: Applications and Services, San Diego: Springer, 373-384.

8. Manovich, L. (2008). Software takes command. Unpublished edition. Accessed on July 7, 2011 from: softwarestudies.com/softbook/manovich_softbook_11_20_2008.pdf.

9. Manovich, L. (2011). Cultural Software. July 2011 edition. Accessed on November 12, 2011 from: http://www.manovich.net/DOCS/Manoich.Cultural_Software.2011.pdf.

10. Mercer, C. (2011). Culturelinks: cultural networks and cultural policy in the digital age, in Cvjetièanin, B (Ed), Networks: The Evolving Aspects of Culture in the 21st Century, 1315 November 2009, Zagreb (Culturelink Joint Publications Series,15). Zagreb: Institute for International Relations, 31-44.

11. Schuch Brunet, K., Freire, J. (2010). Cultura ditigal e geolocalização: a arte ante o contexto técnico-político. Comunicação apresentada ao VI ENECULT, Encontro de Estudos Multidisciplinares em cultura, Facom UFB, 25-27 maio 2010, Salvador da Bahia. Accessed on January 19, 2011 from: http://nomada.blogs.com/home/publicaciones.html.

12. Valentino, P. M (2008). L'impatto della "seconda rivoluzione” informatica su cultura e turismo, in Galluzzi, P., Valentino, P. A(Eds), Galassia Web. La cultura nella rete. Firenze: Giunti, XLI-LXIII.

13. van Kranenburg, R. (2008). New realities, new policies?, in Uzelac, A., Cvjeti

14. anin, B (Eds), Digital Culture: The Changing Dynamics, Institute for International Relations (Culturelink Joint Publications Series,12). Zagreb: Institute for International Relations, 25-41. 